\title{
Analysis of the Dynamic and Energy Characteristics of Water Circulation near the Western Crimea Coast and in the Sevastopol Region Based on the Observational Data Assimilation in the Numerical Model of the Black Sea Dynamics
}

\author{
S. G. Demyshev, N. A. Evstigneeva ${ }^{\bowtie}$, D. V. Alekseev, \\ O. A. Dymova, N. A. Miklashevskaya \\ Marine Hydrophysical Institute of RAS, Sevastopol, Russian Federation \\ $\bowtie$ naevstigneeva@yandex.ru
}

Purpose. The study is aimed at evaluating effectiveness of the procedure of the observational data assimilation using the Kalman filter algorithm as compared to sequential analysis of the hydrophysical fields based on the optimal interpolation method, and at analyzing the mesoscale features of coastal circulation near the western Crimea coast and in the Sevastopol region.

Methods and Results. Based on the hydrodynamic model adapted to the Black Sea coastal zone conditions including the open boundary and on the temperature and salinity data from the hydrological survey in 2007, the dynamic and energy characteristics of the Black Sea coastal circulation were calculated with high spatial resolution (horizontal grid is $\sim 1.6 \times 1.6 \mathrm{~km}$ and 30 vertical horizons). The hydrophysical fields were reconstructed using two algorithms of data assimilation: the sequential optimal interpolation and the modified Kalman filter. The kinetic energy changed mainly due to the wind action, vertical friction and the work of pressure forces; the potential energy - due to the potential energy advection and the horizontal turbulent diffusion. The following circulation features were reconstructed: the anticyclonic eddy with the radius about $15 \mathrm{~km}$ in the Kalamita Bay in the water upper layer, the anticyclonic eddy with the radius about $15 \mathrm{~km}$ between 32.2 and $32.6^{\circ} \mathrm{E}$ in the whole water layer, the intense current near Sevastopol and along the Crimea western coast directed to the north and northwest, and the submesoscale eddies of different signs of rotation in the upper layer.

Conclusions. It is shown that having been taken into account, heterogeneity and non-isotropy of the error estimates of the temperature and salinity fields relative to the correlation function lead to qualitative and quantitative differences in the hydrodynamic fields (amplification of currents, change of the currents' direction and eddy formations were better pronounced). At the same time, the mean square errors of the thermohaline fields' estimates decreased. Formation of the anticyclonic eddy with the radius about $15 \mathrm{~km}$ in the Kalamita Bay could be related to the current shear instability. Submesoscale eddies with the diameters less than $5 \mathrm{~km}$ were formed when the current flowed around the coastline and the bottom topography inhomogeneities.

Keywords: Black Sea, numerical simulation, high spatial resolution, assimilation of observational data, mesoscale and submesoscale eddies

Acknowledgments: the authors are grateful to the reviewers for their helpful comments. The circulation mesoscale features reconstructed using the data of the hydrological survey in 2007 was analyzed at the financial support of the Russian Foundation for Basic Research and the city of Sevastopol within the framework of scientific project No. 18-45-920019. The assimilation procedure based on the Kalman filter was continued to be improved within the framework of the state task on theme No. 0827-2019-0002.

For citation: Demyshev, S.G., Evstigneeva, N.A., Alekseev, D.V., Dymova, O.A. and Miklashevskaya, N.A, 2021. Analysis of the Dynamic and Energy Characteristics of Water Circulation near the Western Crimea Coast and in the Sevastopol Region Based on the Observational Data Assimilation in the Numerical Model of the Black Sea Dynamics. Physical Oceanography, [e-journal] 28(1), pp. 20-36. doi:10.22449/1573-160X-2021-1-20-36

DOI: 10.22449/1573-160X-2021-1-20-36

(C) S. G. Demyshev, N. A. Evstigneeva, D. V. Alekseev, O. A. Dymova, N. A. Miklashevskaya, 2021

(C) Physical Oceanography, 2021 


\section{Introduction}

In order to ensure the safety of navigation and the intensive port operation in Sevastopol, which is the naval base of Russia, it is necessary to analyze and forecast the hydrophysical fields in its coastal zone. Reconstruction of the Black Sea circulation spatial-temporal structure, close to the observed one, provides the determination of the areas meso- and submesoscale eddies generation, frontal zones and jet currents, which is important when solving the problems related to navigation, construction of coastal structures, mining, forecasting the impact of pollutant emergency emissions on marine environment. The synthesis of a numerical model of high spatial resolution and hydrological data makes it possible to effectively solve these problems.

Calculations of hydrophysical fields based on the assimilation of observational data in numerical models were carried out earlier. In works [1, 2], the dynamicstochastic models of ocean processes based on the adaptive Kalman filtering algorithm are presented. In [3], an algorithm for four-dimensional analysis of density fields and currents and the results of its implementation based on data from the POLYMODE test site are presented. On the basis of studies [3-5] in [6], a fourdimensional analysis with the assimilation of observational data on temperature and salinity for the summer season of 1984 was carried out, and synoptic features of the Black Sea circulation were studied. In [7], the problem of the integrated use of temperature, salinity and current velocity measurements at the POLYMODE test sites is considered when these data are assimilated into a model based on Kalman filter. In [8], the optimal interpolation method was applied to assimilate the observational data of level anomalies in the Atlantic Ocean into the HYCOM hydrodynamic ocean model. It is revealed that the obtained level fields were characterized by pronounced mesoscale variability. It is demonstrated in [9] that the method of observational data assimilation based on the application of the Fokker - Planck equation and extended Kalman filter method give more accurate results than the optimal interpolation method. The problem of the data variational assimilation on the sea surface temperature in the model of the Black Sea dynamics aimed at reconstructing the surface fluxes was formulated in [10]. In [11], a method for modeling the dynamic processes on the Earth's surface, based on the acquisition and assimilation of data by the model during the development of the process, is proposed. Data assimilation is provided by using a recurrent neural network and Kalman filtering. In [12], a new version of the oceanographic data assimilation system developed at the Hydrometeorological Center of Russia is presented. Assimilation is carried out within the framework of a sequential cyclic analysis - forecast - analysis scheme, the main components of which are the procedures for preparing the observational data obtained on-line, the variational data analysis scheme and the ocean general circulation model. In [13], an algorithm for studying the optimal solution sensitivity to errors of observational data in the problem of assimilating sea surface temperature in order to reconstruct the heat fluxes on the surface, and an example of solving the optimal problem of the World Ocean hydrodynamics, taking into account the assimilation of climatic observations of temperature and salinity, is given. In [14], the results of the Black Sea dynamics analysis for 1993-2012, obtained on the basis of numerical modeling by the circulation model with the assimilation of satellite measurements of free surface elevation and sea surface temperature, are presented. In [15], a parallel 
implementation of the ensemble interpolation method for assimilating observational data in a eddy-resolving model of ocean dynamics is proposed, and the results of numerical experiments in the North Atlantic when assimilating the AVISO satellite altimetry data from the Jason-1 satellite are analyzed. In [16], the algorithms for variational assimilation of temperature and level data at the liquid boundary are formulated, and the results of numerical experiments on the use of algorithms in the Baltic Sea circulation model are presented.

The procedure of four-

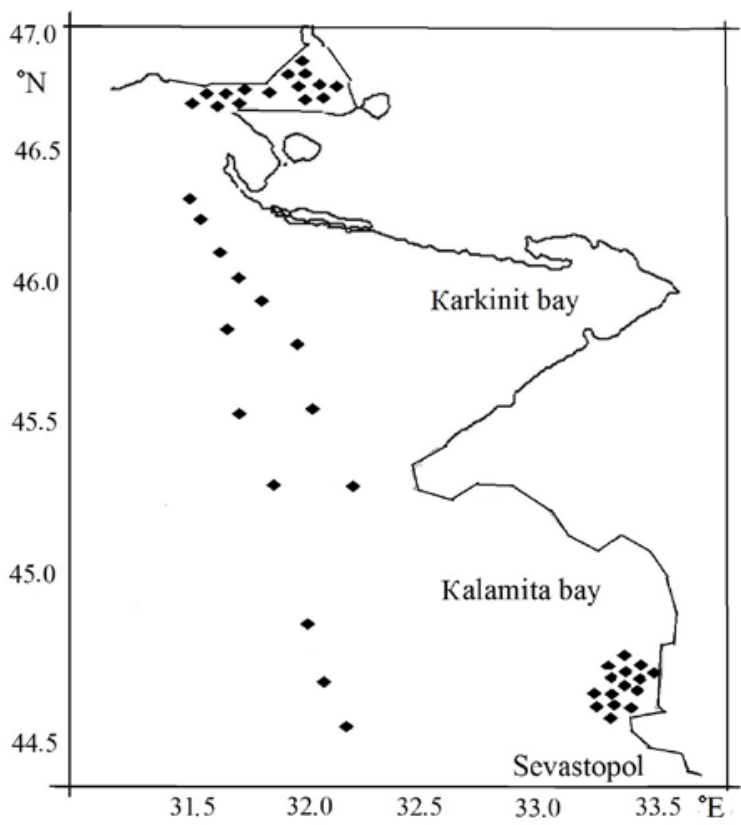

F i g. 1. Scheme of stations, September 16-22, $2007^{1}$ dimensional assimilation of observational data, developed in [3-6], is used to analyze the hydrological survey carried out at $\mathrm{R} / \mathrm{V}$ Eksperiment in September 2007, during which experimental data on temperature and salinity in the Black Sea coastal area were obtained (Fig. $1^{1}$ ).

Reconstruction of temperature, salinity and current velocity fields is carried out on the basis of two algorithms for assimilating temperature and salinity observation data acquired in September 2007 (sequential optimal interpolation and a modified Kalman filter). A possible mechanism of generation of mesoscale and submesoscale eddies and jet currents near the western coast of Crimea and in the Sevastopol region are studied.

\section{Numerical model parameters and conditions for carrying out numerical experiments}

The applied numerical model of the Black Sea dynamics, developed at Marine Hydrophysical Institute (MHI) and based on the complete equations of ocean thermohydrodynamics in the Boussinesq approximation, hydrostatics and incompressibility of the sea water in the Gromeka - Lamb form, boundary conditions on the surface, at the bottom and on solid side walls in detail are described in [17].

${ }^{1}$ Evstigneeva, N. and Demyshev, S. Analysis of Circulation near the Coast of the Western Crimea and the Region of Sevastopol with Assimilation of Temperature and Salinity Observations. IOP Conference Series: Earth and Environmental Sciences, 386(conference 1), 012047. Available at: https://iopscience.iop.org/article/10.1088/1755-1315/386/1/012047 [Accessed: 11 January 2021]. 
The computational domain was located between $28.7^{\circ}$ and $33.8^{\circ} \mathrm{E}$ meridians and $44.4^{\circ}$ and $47^{\circ} \mathrm{N}$ parallels (the refined bottom topography of $\sim 1.6 \mathrm{~km}$ resolution was taken into account). The calculations were carried out on $\sim 1.6 \times 1.6 \mathrm{~km}$ horizontal grid (302 × 196 points). The time step of $30 \mathrm{~s}$ was selected. Turbulent viscosity and horizontal diffusion were selected in the form of a harmonic operator, the values of the coefficients were equal. The integration period of the model equations is 10 days (from September 14 to September 24, 2007). Vertical horizontal components of the current velocity, temperature and salinity were calculated for 30 horizons: 1 ; 3; 5; 7; 10; 13; 16; 20; 25; 30; 36; 42; 48; 55; 65; 80; 95; 120; 150; $200 ; 300 ; \ldots ; 1200 \mathrm{~m}$. The vertical component of velocity was calculated for intermediate horizons. The coefficients of turbulent momentum exchange and vertical diffusion were calculated in accordance with the Philander - Pakanowski approximation [18] with the following selected parameter values: $R_{0}=1$, $v_{0}=10 \mathrm{~cm}^{2} / \mathrm{s}, \quad v_{1}=5 \mathrm{~cm}^{2} / \mathrm{s}, \kappa_{1}=1 \mathrm{~cm}^{2} / \mathrm{s}$.

In order to set the initial conditions of the problem and boundary conditions at the open boundary of the region, the fields of currents, temperatures, salinity obtained by the model for the entire sea on $5 \times 5 \mathrm{~km}$ horizontal grid were used [19]. On the open southern boundary (corresponding to $44.4^{\circ} \mathrm{N}$ parallel), the following conditions were set: for the sections of the boundary where the water inflows $(v>0)$, the velocity components, temperature, salinity were set (Dirichlet conditions); where water flows out $(v<0)$, the conditions $\partial u / \partial n=0, \partial v / \partial n=0$ for $u, v$ were set; to determine $T$ and $S$ at the open boundary, the radiation conditions were set. The calculations took into account the runoffs of Danube, Dnieper, Dniester and Southern Bug. On the sea surface, the fields of wind stress, heat fluxes, short-wave radiation, precipitation and evaporation, obtained from the data of Aladin regional atmospheric model [20], were set every day. The flux of shortwave radiation in the model was taken into account explicitly (a term was added to the heat transport equation, which ensures its consideration), and all other components of the heat flux, including the long-wave radiation flux, were included in the term $Q^{T}$, for which the condition $\kappa^{T} T_{z}=Q^{T}-R$, where $R$ is the shortwave radiation on the surface, was set on the surface.

The data from a hydrological survey carried out at R/V Eksperiment in September 2007 on the vertical and spatial distribution of temperature and salinity, taken from MHI data bank [21], is used in the work. The maximum depth to which the probings were carried out varied from 5 to $300 \mathrm{~m}$, the number of stations was 44 . The measurements were carried out using SHIK-1 CTD probe (shelf measuring complex).

In order to implement the procedure for assimilating the data from field observations, we used a four-dimensional analysis procedure [3, 4], based on a modified Kalman filter. Two numerical experiments were carried out. In experiment 1 , the variance of the errors in the temperature and salinity estimates was assumed to be constant and equal to unity (the fields of errors in the estimates of the fields were assumed to be homogeneous and isotropic with regards to the covariance function). In experiment 2, the inhomogeneity and anisotropy of the errors in the estimates of the temperature and salinity fields were taken into 
account (the variances of the errors in the estimates were calculated from the corresponding equations).

From the analysis of the statistical structure of the fields (calculation of the spatial correlation functions of temperature and salinity fields), the correlation radius was determined to be $\sim 20 \mathrm{~km}$. The covariance functions of thermohaline fields were approximated by a function of exponential type $\exp \left(-\lambda\left[\left(x-x^{\prime}\right)^{2}+\left(y-y^{\prime}\right)^{2}\right]\right)[4]$, where $\lambda$ is the dimensional parameter (equal to $\left.0.016 \cdot(\Delta x)^{-2}\right)$, selected at 0.1 level of the correlation function value [4].

Hydrological survey data were grouped by date (six groups in total), and assimilation was carried out once a day: September 16 - 3 stations, September 17 - 7, September 18 - 8, September 19 - 7, September 20 - September 4 and 22 15 stations.

\section{The procedure for observational data assimilation taking into account heterogeneity and the anisotropy of the estimates of the temperature and salinity fields based on modified Kalman filter}

A detailed procedure for assimilating observational data, taking into account the inhomogeneity and anisotropy of errors in the estimates of temperature and salinity fields, is given in [3, 4], following which we describe the assimilation scheme used in this work. The modified Kalman filter is understood as the Kalman filter technique, which is based on solving equations for the variance of errors in the estimates of temperature and salinity fields.

Suppose that at discrete moments of time in $M$ different points in space $\vec{x}_{1}, \vec{x}_{2}, \ldots, \vec{x}_{M}(\vec{x}=(x, y, z))$ the measurement data $T, S$ are available. By the time of $\left(t_{n}\right)$ data acquisition, thermohaline fields are already calculated using the equations of MHI model [17]. Then T, $S$ are corrected by the formulas [5, p. 121]

$$
\begin{aligned}
& T\left(\vec{x}, t_{n}^{+}\right)=T\left(\vec{x}, t_{n}^{-}\right)+\sum_{m=1}^{M} \Delta_{m}^{T}\left(\vec{x}, t_{n}^{-}\right)\left[T\left(\vec{x}_{m}, t_{n}\right)-T\left(\vec{x}_{m}, t_{n}^{-}\right)\right], \\
& S\left(\vec{x}, t_{n}^{+}\right)=S\left(\vec{x}, t_{n}^{-}\right)+\sum_{m=1}^{M} \Delta_{m}^{S}\left(\vec{x}, t_{n}^{-}\right)\left[S\left(\vec{x}_{m}, t_{n}\right)-S\left(\vec{x}_{m}, t_{n}^{-}\right)\right] .
\end{aligned}
$$

The first terms in square brackets in expressions (1) and (2) are the data of $T, S$ measurements at $t_{n}$ moment of time. The second ones are the temperature and salinity fields calculated by the numerical model at the same moment in time. The minus sign of $t_{n}$ means that the corresponding fields were obtained without taking into account the measurement data at the time of the data acquisition. Plus means that the calculation of the desired characteristics was carried out taking into account $t_{n}$ data of field observations available at the time. $M$ is the number of measurements, determined by the correlation radius, by which the weighting factors were calculated. The weighting factors were determined from the relations [5, p. 123] 


$$
\begin{gathered}
\Delta_{m}^{T}\left(\vec{x}, t_{n}^{-}\right)=\sum_{l=1}^{M} P_{T T}\left(\vec{x}, \vec{x}_{m}, t_{n}^{-}\right)\left[P_{T T}\left(\vec{x}_{m}, \vec{x}_{l}, t_{n}^{-}\right)+R_{T}\left(\vec{x}_{m}, \vec{x}_{l}, t_{n}^{-}\right)\right]^{-1}, \\
\Delta_{m}^{S}\left(\vec{x}, t_{n}^{-}\right)=\sum_{l=1}^{M} P_{S S}\left(\vec{x}, \vec{x}_{m}, t_{n}^{-}\right)\left[P_{S S}\left(\vec{x}_{m}, \vec{x}_{l}, t_{n}^{-}\right)+R_{S}\left(\vec{x}_{m}, \vec{x}_{l}, t_{n}^{-}\right)\right]^{-1}, m=1, \ldots, M,
\end{gathered}
$$

where $R_{T}, R_{S}$ are covariance functions of temperature and salinity measurement errors, respectively; $P_{T T}, P_{S S}$ are covariance functions of errors in estimates of temperature and salinity fields, which are approximated by the following expressions [3, 4]:

$$
\begin{gathered}
P_{T T}\left(\vec{x}, \vec{x}^{\prime}, t\right) \approx D_{T}(\vec{x}, t) D_{T}\left(\vec{x}^{\prime}, t\right) P_{T}\left(x-x^{\prime}, y-y^{\prime}\right), \\
P_{S S}\left(\vec{x}, \vec{x}^{\prime}, t\right) \approx D_{S}(\vec{x}, t) D_{S}\left(\vec{x}^{\prime}, t\right) P_{S}\left(x-x^{\prime}, y-y^{\prime}\right),
\end{gathered}
$$

where $D_{T}, D_{S}$ are the fields of normalized root-mean-square errors of estimates of $T$ and $S$ fields; $P_{T}, P_{S}$ are the covariance functions of the temperature and salinity fields.

The equations for calculating the error variance in the estimates of the temperature and salinity fields are as follows:

$$
\begin{gathered}
\partial D_{T}^{2} / \partial t+\partial\left(D_{T}^{2} u\right) / \partial x+\partial\left(D_{T}^{2} v\right) / \partial y+\partial\left(D_{T}^{2} w\right) / \partial z=k_{H} \Delta D_{T}^{2}+\partial\left(k^{\mathrm{V}} \partial D_{T}^{2} / \partial z\right) / \partial z \\
\partial D_{S}^{2} / \partial t+\partial\left(D_{S}^{2} u\right) / \partial x+\partial\left(D_{S}^{2} v\right) / \partial y+\partial\left(D_{S}^{2} w\right) / \partial z=k_{H} \Delta D_{S}^{2}+\partial\left(k^{\mathrm{V}} \partial D_{S}^{2} / \partial z\right) / \partial z
\end{gathered}
$$

where $k_{\mathrm{H}}, k^{\mathrm{V}}$ are the coefficients of turbulent diffusion. Advective terms $D_{T}, D_{S}$ of transport - diffusion equations were approximated by TVD-schemes [22].

In the moments of observational data acquisition, $D_{T}, D_{S}$ were corrected by the following relations

$$
\begin{aligned}
& D_{T}^{2}\left(\vec{x}, t_{n}^{+}\right)=D_{T}^{2}\left(\vec{x}, t_{n}^{-}\right)-\sum_{m=1}^{M} \Delta_{m}^{T}\left(\vec{x}, t_{n}^{-}\right) P_{T}\left(x_{m}-x, y_{m}-y\right), \\
& D_{S}^{2}\left(\vec{x}, t_{n}^{+}\right)=D_{S}^{2}\left(\vec{x}, t_{n}^{-}\right)-\sum_{m=1}^{M} \Delta_{m}^{T}\left(\vec{x}, t_{n}^{-}\right) P_{S}\left(x_{m}-x, y_{m}-y\right) .
\end{aligned}
$$

Thus, before the moment of the observational data acquisition, the fields $T, S$ were forecasted using the equations of the hydrodynamic model. At the moment of assimilation, according to relations (1)-(10), the fields $T, S$ were corrected taking into account the correlation radius.

As a first approximation in the problem, it was assumed that the conditions $\partial D_{T}^{2} / \partial n=0, \partial D_{S}^{2} / \partial n=0$ were set on all boundaries.

At the initial moment of time, the covariance functions were taken to be equal to the covariance functions of the field itself (that is, the variance of errors in the estimates of the temperature and salinity fields was equal to unity). The value of the horizontal turbulent diffusion coefficient of the variance of $k_{\mathrm{H}}$ errors in 
formulas (7), (8) was chosen to be equal to $10^{5} \mathrm{~cm}^{2} / \mathrm{s}$. The vertical diffusion coefficients of error variance were calculated in accordance with the Philander Pakanowski approximation [18].

In order to illustrate the calculation of root-mean-square error fields of the temperature field estimates, Fig. 2 is given. It shows the fields for September 17 and 20, 2007 in the area where hydrological data were assimilated.
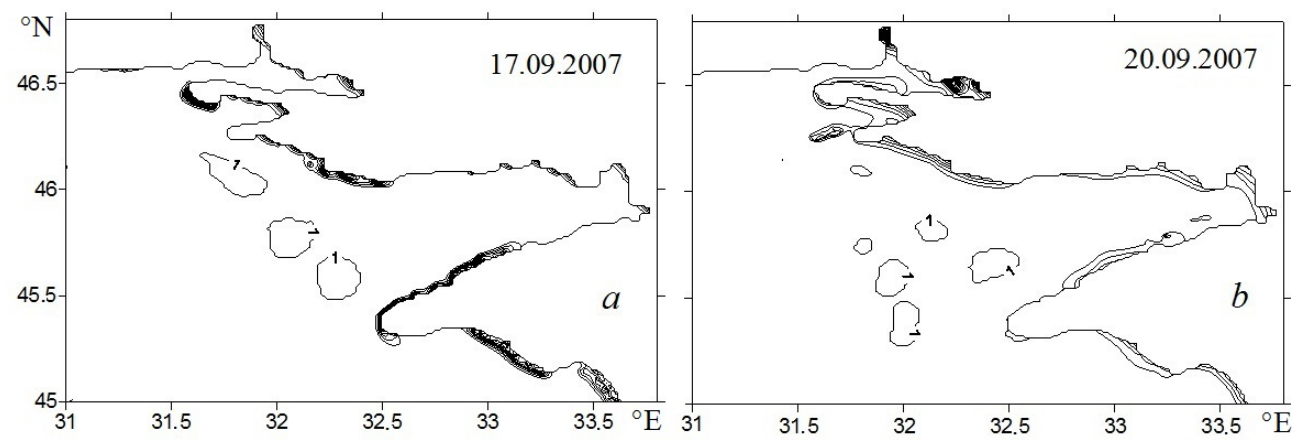

F i g. 2. Fields of the mean square errors of the temperature fields' estimates at the $3 \mathrm{~m}$ depth: $a-$ 17.09.2007; $b-20.09 .2007$ ( 1 - value of the mean square error of the temperature field estimate)

\section{Results of numerical experiments for 2007}

For reconstructing the fields of currents, temperature and salinity in the Black Sea coastal region based on MHI hydrodynamic model with the assimilation of data from hydrological survey, two numerical experiments were carried out. In the first experiment, the correlation functions of the errors in the estimates of thermohaline fields were assumed to be homogeneous and isotropic (that is, the variance of the errors in the estimates of the fields was equal to unity); in the second experiment the covariance functions of the errors in the estimates of temperature and salinity fields were calculated by formulas (7)-(10).

When integrating the model equations for each moment of assimilation for all horizons $k$ for which the measurement data were available, the following values were calculated in the experiments:

$$
\sigma_{T}=\left\{\frac{1}{N-1} \sum_{1}^{N}\left[\left|T_{\text {mod }}^{n}-T_{\text {data }}^{n}\right|-\delta_{T}^{n}\right]^{2}\right\}^{1 / 2}, \sigma_{S}=\left\{\frac{1}{N-1} \sum_{1}^{N}\left[\left|S_{\text {mod }}^{n}-S_{\text {data }}^{n}\right|-\delta_{S}^{n}\right]^{2}\right\}^{1 / 2},
$$

where $N$ is the total number of stations at $k$ model horizon; $T_{\bmod }^{n}$ and $S_{\bmod }^{n}$ are the values calculated by the model for $n^{\text {th }}$ day; $T_{\text {data }}^{n}$ and $S_{\text {data }}^{n}$ are the observation data referred to one point in time;; $\delta_{T}^{n}, \delta_{S}^{n}$ are average errors of estimates of $T, S$ fields.

In Table 1 and $2 \sigma_{T}$ and $\sigma_{S}$ calculated values averaged for 1-10, 10-20, 2030 and $30-100 \mathrm{~m}$ layers are given. 
Values of $\sigma_{T}\left({ }^{\circ} \mathbf{C}\right)$ and $\sigma_{S}(\%)$ calculated in experiment $1\left(D_{T}^{2}=1, D_{S}^{2}=1\right)$

\begin{tabular}{c|c|c|c|c|c|c|c|c}
\hline \multirow{2}{*}{ Date } & \multicolumn{5}{c|}{$\sigma_{T}$} & \multicolumn{4}{c}{$\sigma_{S}$} \\
\cline { 2 - 10 } & \multicolumn{5}{|c}{ Layer (m) } & \multicolumn{5}{c}{ Layer (m) } \\
\cline { 2 - 10 } & $1-10$ & $10-20$ & $20-30$ & $30-100$ & $1-10$ & $10-20$ & $20-30$ & $30-100$ \\
\hline 16.09 .2007 & 3.68 & 5.45 & 3.42 & 0.06 & 3.15 & 0.56 & 0.34 & 0.07 \\
17.09 .2007 & 3.39 & 5.29 & 3.80 & 0.43 & 2.95 & 0.28 & 0.28 & 0.13 \\
18.09 .2007 & 3.42 & 5.08 & 3.70 & 0.42 & 1.80 & 0.68 & 0.39 & 0.14 \\
19.09 .2007 & 3.07 & 4.13 & 3.22 & 0.41 & 1.74 & 0.68 & 0.38 & 0.15 \\
20.09 .2007 & 2.61 & 3.16 & 2.47 & 0.41 & 3.28 & 0.46 & 0.24 & 0.17 \\
22.09 .2007 & 1.78 & 1.72 & 2.10 & 0.29 & 3.17 & 0.35 & 0.18 & 0.12 \\
\hline
\end{tabular}

Table 2

The values of $\sigma_{T}\left({ }^{\circ} \mathrm{C}\right)$ и $\sigma_{S}(\%)$, calculated in the experiment $2\left(D_{T}^{2} \neq 1, D_{S}^{2} \neq 1\right)$

\begin{tabular}{l|c|c|c|c|c|c|c|c}
\hline \multirow{2}{*}{ Date } & \multicolumn{5}{c|}{$\sigma_{T}$} & \multicolumn{5}{c}{$\sigma_{S}$} \\
\cline { 2 - 10 } & \multicolumn{3}{c}{ Layer (m) } & \multicolumn{5}{c}{ Layer (m) } \\
\cline { 2 - 10 } & $1-10$ & $10-20$ & $20-30$ & $30-100$ & $1-10$ & $10-20$ & $20-30$ & $30-100$ \\
\hline 16.09 .2007 & 3.68 & 5.45 & 3.42 & 0.06 & 3.15 & 0.56 & 0.34 & 0.07 \\
17.09 .2007 & 3.28 & 5.14 & 3.42 & 0.43 & 2.95 & 0.27 & 0.26 & 0.12 \\
18.09 .2007 & 3.26 & 4.82 & 3.42 & 0.42 & 1.60 & 0.52 & 0.32 & 0.13 \\
19.09 .2007 & 3.26 & 3.93 & 2.95 & 0.41 & 1.66 & 0.51 & 0.34 & 0.15 \\
20.09 .2007 & 3.26 & 2.98 & 2.16 & 0.41 & 2.83 & 0.37 & 0.23 & 0.17 \\
22.09 .2007 & 1.60 & 1.54 & 1.86 & 0.29 & 2.75 & 0.28 & 0.16 & 0.12 \\
\hline
\end{tabular}

Analyzing the data obtained in two experiments and presented in Table. 1 and 2 , we note that the largest values of $\sigma_{T}$ errors were observed in 10-20 m water layer, $\sigma_{S}$ errors - in the upper layer (by the end of the considered period of time, the values of error moduli were decreasing at all horizons).

Comparing $\sigma_{T}$ values obtained in experiments 1 and 2, we note that the errors in the temperature field in the upper water layer on September 18 decreased by PHYSICAL OCEANOGRAPHY VOL. 28 ISS. 1 (2021) 
$5 \%$, and on September 20 and 22 - by $11 \%$, in 10-20 m water layer on September 22 - by $10 \%$, in 20-30 m water layer on September 18, decreased by $13 \%$, on September 20 and 22 - by $12 \%$. Accordingly, the errors in the salinity field in the upper water layer in the field on September 18 decreased by $11 \%$, on September 20 and 22 - by 13\%, in 10-20 m water layer on September 22 - by $20 \%$, in 20-30 m water layer on 22 September - by $12 \%$. In the layer below $30 \mathrm{~m}$ horizon the differences in the experimental results are insignificant.

In addition to quantitative differences in the experimental results, qualitative differences in hydrophysical fields were also obtained. In particular, when comparing the current fields calculated in two numerical experiments, the following circulation features were noted: strengthening of currents, change of current direction, more pronounced eddy formations (eg, Fig. 3). A correspondence between the results of experiment 2 and satellite observations in September 2007 of $N O A A-15$ and $N O A A-18$ with $1 \mathrm{~km}$ resolution was obtained.

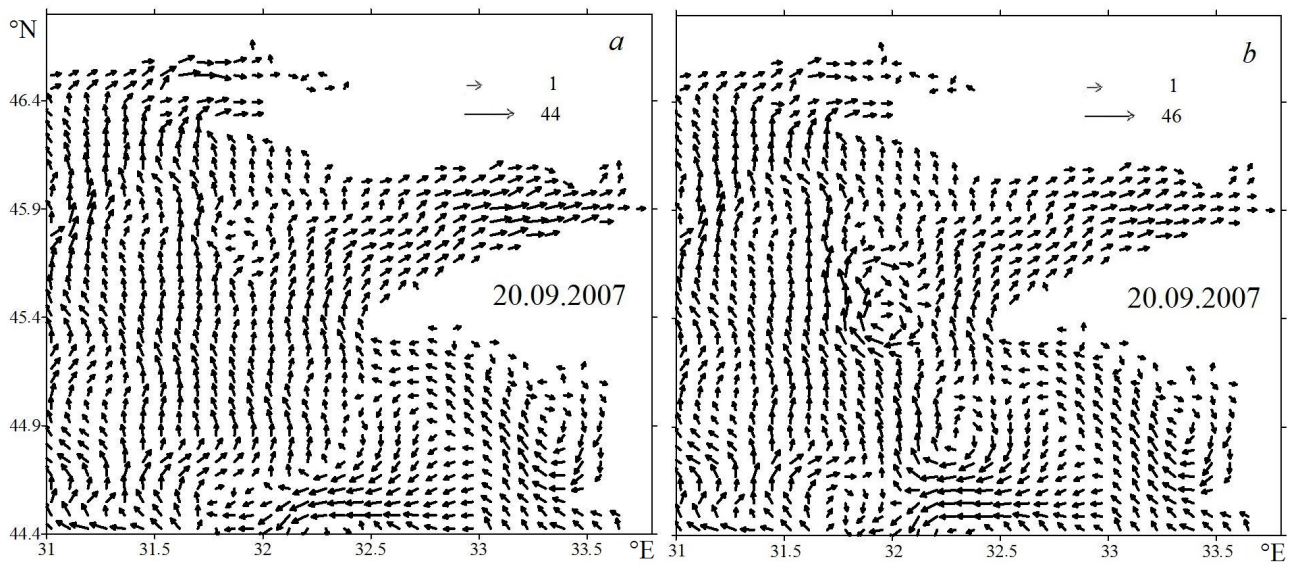

F i g. 3. Fields of currents (cm/s) at the $3 \mathrm{~m}$ depth on September 20, 2007 for experiment $1(a)$ and experiment $2(b)$. Every fifth arrow is shown

\section{Energetics analysis}

In [23, 24], finite-difference analogs of the equations for changing the kinetic and potential energy density were written. On their basis the energy characteristics in this work were calculated. Further in the text, the term "energy" means the energy density, that is, the energy of a unit volume. The symbolic notation of the kinetic energy budget equation (KE) has the form

$$
E_{t}+A d v(P+E)=\Pi \leftrightarrow E+F_{\mathrm{Bfr}}^{\tau}(E)-\operatorname{Diss}_{\mathrm{Ver}}(E)-\operatorname{Diss}_{\mathrm{Hor}}(E)+D_{\mathrm{Fic}}(E),
$$

where $\operatorname{Adv}(P)$ is the work of pressure force; $A d v(E)$ is a kinetic energy advection; $\Pi \leftrightarrow E$ is a work of buoyancy force; $F_{\mathrm{Bfr}}^{\tau}(E)$ is a KE variation due to vertical and horizontal internal friction; $\operatorname{Diss}_{\text {Ver }}(E)$ and $\operatorname{Diss}_{\mathrm{Hor}}(E)$ are an energy dissipation due to vertical and horizontal internal friction; $D_{\text {Fic }}(E)$ is a kinetic energy redistribution in the basin and its loss due to the friction against the side walls. 
Potential energy $(\mathrm{PE})$ variation is described by the following equation:

$$
\begin{aligned}
\Pi_{t}+\operatorname{Adv}(\Pi)=- & \Pi \leftrightarrow E+\operatorname{Diff}_{\mathrm{Hor}}(\Pi)+\operatorname{Diff}_{\mathrm{Ver}}^{\text {Fluxes }}(\Pi)+\operatorname{Diff}_{\mathrm{Ver}}^{\kappa_{\mathrm{V}}}(\Pi)+ \\
& +\operatorname{Diff}_{\mathrm{Ver}}^{\text {Bot-Sur }}(\Pi)+\operatorname{Diff}_{\mathrm{Ver}}^{\text {Add }}(\Pi),
\end{aligned}
$$

where $\operatorname{Adv}(\Pi)$ is an advection of potential energy; $\operatorname{Diff} \mathrm{Hor}_{\mathrm{Ho}}(\Pi)$ is $\mathrm{PE}$ variation due to horizontal turbulent diffusion; Diff $f_{\text {Ver }}^{\text {Fluxes }}(\Pi)$ is PE variation caused by buoyancy fluxes and vertical internal diffusion; Diff Ver $_{\text {Bot-Sur }}(\Pi)$ is PE variation caused by the difference between the bottom and surface density; $\operatorname{Diff} f_{\text {Ver }}^{\mathrm{K}_{\mathrm{V}}}(\Pi)$ is PE variation due to inhomogeneity of vertical turbulent diffusion coefficient by depth; $\operatorname{Diff}_{\text {Ver }}^{\text {Add }}(\Pi)$ is an additional term due to non-linear density dependence on temperature and salinity.

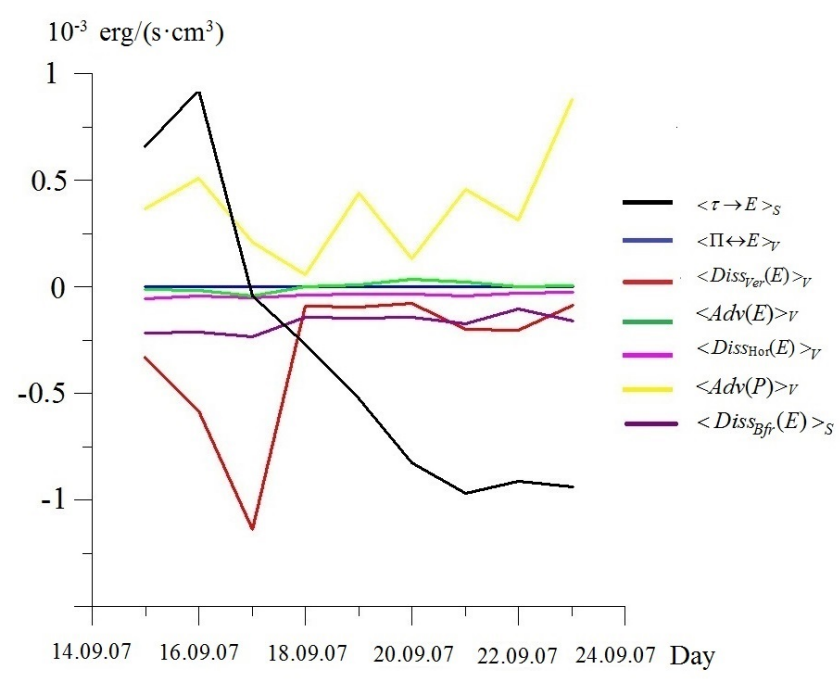

F i g. 4. Temporal change of the integrated components of the kinetic energy budget equation normalized to the domain volume

We are to analyze the temporal change of the integral components of KE budget equation for the considered period of time, calculated according to experiment 2 data (Fig. 4). The angle brackets denote the integration operation. Note that the advective terms do not vanish during integration due to the river inflow.

The main contribution to the KE was made by the pressure force work $<\operatorname{Adv}(P)>_{V}$, and in the period from September 15 to 17 - also the wind force work $<\tau \rightarrow E\rangle_{S}$, the velocity of which reached its maximum value of $11 \mathrm{~m} / \mathrm{s}$ on September 17. The loss of energy occurred due to vertical internal friction, changes in $\mathrm{KE}-$ due to friction against the bottom $\left\langle\operatorname{Diss}_{\mathrm{Bfr}}(E)\right\rangle_{S}$ and the term $<\tau \rightarrow E>_{S}$. The contribution of buoyancy force work, advection of kinetic energy and energy dissipation due to horizontal internal friction was insignificant. 


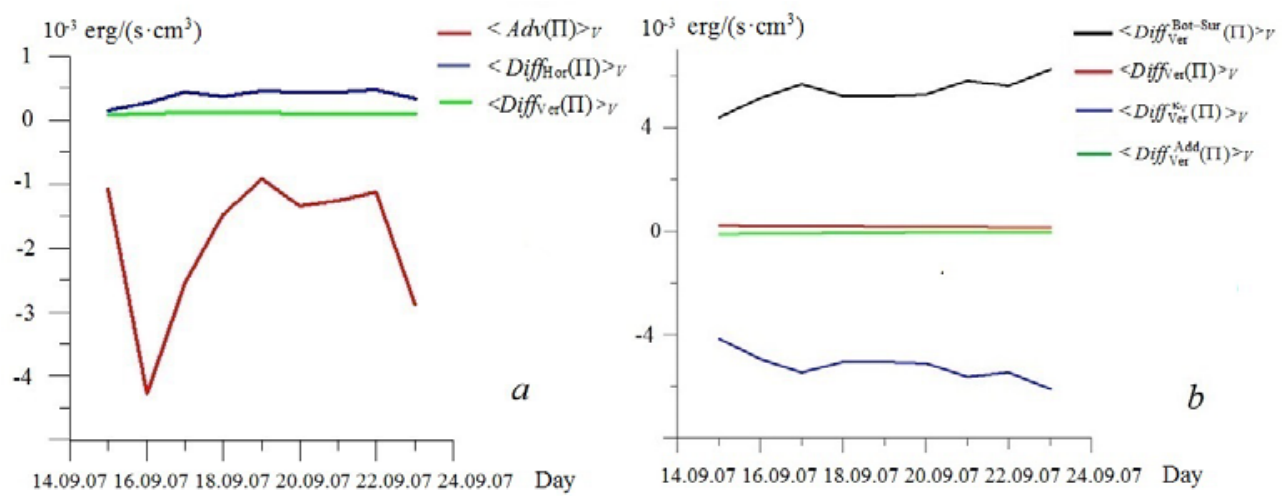

F i g. 5. Temporal change of the integrated components of the potential energy budget equation normalized to the domain volume $(a)$, the volume-normalized total integrated vertical diffusion and the terms involved in its calculation $(b)$

The variation in potential energy was mainly due to the advection of potential energy and horizontal turbulent diffusion (Fig. 5, a).

When calculating the total vertical diffusion in the PE budget equation (Fig. 5, b), the main contribution was made by the term characterizing the density difference on the surface and at the bottom of the sea (its maximum value was $6.2 \cdot 10^{-3} \mathrm{erg} /\left(\mathrm{s}^{\cdot} \mathrm{cm}^{3}\right)$. It was compensated by a term depending on the change in the diffusion coefficient with depth (its maximum value was $6.1 \cdot 10^{-3} \mathrm{erg} /\left(\mathrm{s}^{\cdot} \mathrm{cm}^{3}\right)$. The potential energy variation due to $\left\langle\operatorname{Diff} f_{\mathrm{Ver}}^{\text {Add }}(\Pi)\right\rangle_{V}$ term was relatively small.

Further, for each day of the integration period the three-dimensional fields of the circulation energy characteristics, obtained in a numerical experiment on the calculation of hydrophysical fields with the data assimilation of hydrological measurements carried out in September 2007, taking into account the inhomogeneity and anisotropy of errors in the estimates of the temperature and salinity fields for the region located between $32.2^{\circ} \mathrm{E}$ and $33.8^{\circ} \mathrm{E}$ meridians and $44.4^{\circ} \mathrm{N}$ and $45.4^{\circ} \mathrm{N}$ parallels, are analyzed.

According to the results obtained in the calculation in this study and in [25], the following circulation features were revealed: an anticyclonic eddy with a radius of about $15 \mathrm{~km}$ in the upper water layer in the Kalamita Bay, an anticyclonic eddy with a radius of about $15 \mathrm{~km}$ in the entire water layer between $32.2^{\circ} \mathrm{E}$ and $32.4^{\circ} \mathrm{E}$ related to the Rim Current meandering. On September 22 and 23, in the upper 36-meter layer the current, directed to the north and northwest, increased near Sevastopol and along the western coast of Crimea. During the entire calculation, small-scale anticyclonic and cyclonic eddies could be generated in the upper layer along the coast.

The local baroclinic deformation radius $\left(R_{d}\right)$ for the selected coastal region of the Black Sea is $\sim 10 \mathrm{~km}$. We will refer to mesoscale eddies as eddies whose radius is greater than the local baroclinic Rossby deformation radius, and the Rossby number is much less than unity $\left(R>R_{d}, R_{o}<1\right)$. The eddies whose radius is less 
than $R_{d}$ one and the Rossby number is of the order of unity ( $R<R_{d}, R_{o} \approx 1$ ) will be classified as submesoscale eddies.

Now we are to analyze the changes in the fields of instantaneous values of the terms from the kinetic and potential energy budget equations. As an illustration, we present the current fields and energy fields at $5 \mathrm{~m}$ horizon from September 17 and 22, 2007 (Fig. 6), on which the listed circulation features were more pronounced (Fig. 6, $a$ and $f$ ).

The fields $\operatorname{Adv}(P)$ were characterized by significant variability and alternation of areas with positive and negative values (Fig. 6, $b$ and $g$ ). The maximum modulus value on September 17 was $8 \cdot 10^{-3} \mathrm{erg} /\left(\mathrm{s}^{\cdot} \mathrm{cm}^{3}\right)$, on September 22 it increased to $2 \cdot 10^{-2} \mathrm{erg} /\left(\mathrm{s} \cdot \mathrm{cm}^{3}\right)$. The predominance of the pressure force work contribution (Fig. 4) in the kinetic energy increase can be explained as follows. For given latitudes, the dynamic level in the first approximation can be written down as $\zeta^{d}=-\frac{1}{\rho_{0}} \int_{0}^{H} \rho d z$, then the pressure anomaly can be represented as $P=-g \cdot \int_{z}^{H} \rho d z$. Consequently, the pressure force work largely depends on the difference in the bottom topography. Between $31^{\circ} \mathrm{E}$ and $33.5^{\circ} \mathrm{E}$ meridians a drop of depths takes place. The depth there varies from 100 to $1300 \mathrm{~m}$. The greatest values of the pressure force work were observed in this area.

The advection contribution to the kinetic energy variation rate was insignificant; on September 17, $A d v(E)$ field was characterized by a maximum modulus value of $5 \cdot 10^{-4} \mathrm{erg} /\left(\mathrm{s} \cdot \mathrm{cm}^{3}\right)$, and on September 22 it increased to $3 \cdot 10^{-3} \mathrm{erg} /\left(\mathrm{s} \cdot \mathrm{cm}^{3}\right)$, which is due to the strengthening of currents in this region (Fig. 6, $c$ and $h$ ).

According to Fig. 4, the inflow of energy from the wind was compensated by vertical friction, the maximum in modulus $\operatorname{Diss}_{\text {Ver }}(E)$ values were reached on September 17. On this day, the central region was characterized by an intense work of vertical dissipation, the maximum $\operatorname{Diss}_{\text {Ver }}(E)$ value by modulus was $1.8 \cdot 10^{-2} \mathrm{erg} /\left(\mathrm{s}^{\cdot} \mathrm{cm}^{3}\right)$, along the coast the values decreased (Fig. 6, d). During September 22, the variability of $\operatorname{Diss}_{\mathrm{Ver}}(E)$ field was insignificant (Fig. 6, i), the modulus values did not exceed $2 \cdot 10^{-3} \mathrm{erg} /\left(\mathrm{s} \cdot \mathrm{cm}^{3}\right.$ ) (decreased by an order of magnitude compared to the values from September 17).

The advection fields of the potential energy $A d v(\Pi)$ had a complex and timevariable spatial structure: both areas with positive values and areas with negative values were observed (Fig. 6, $e$ and $j$ ). The maximum $A d v(\Pi)$ value on September 17 was $1 \cdot 10^{-3} \mathrm{erg} /\left(\mathrm{s}^{\cdot} \mathrm{cm}^{3}\right)$ in the eastern part of the region; on September 22 it increased to $4 \cdot 10^{-3} \mathrm{erg} /\left(\mathrm{s}^{\cdot} \mathrm{cm}^{3}\right)$ (due to the intensification of currents in this region). 

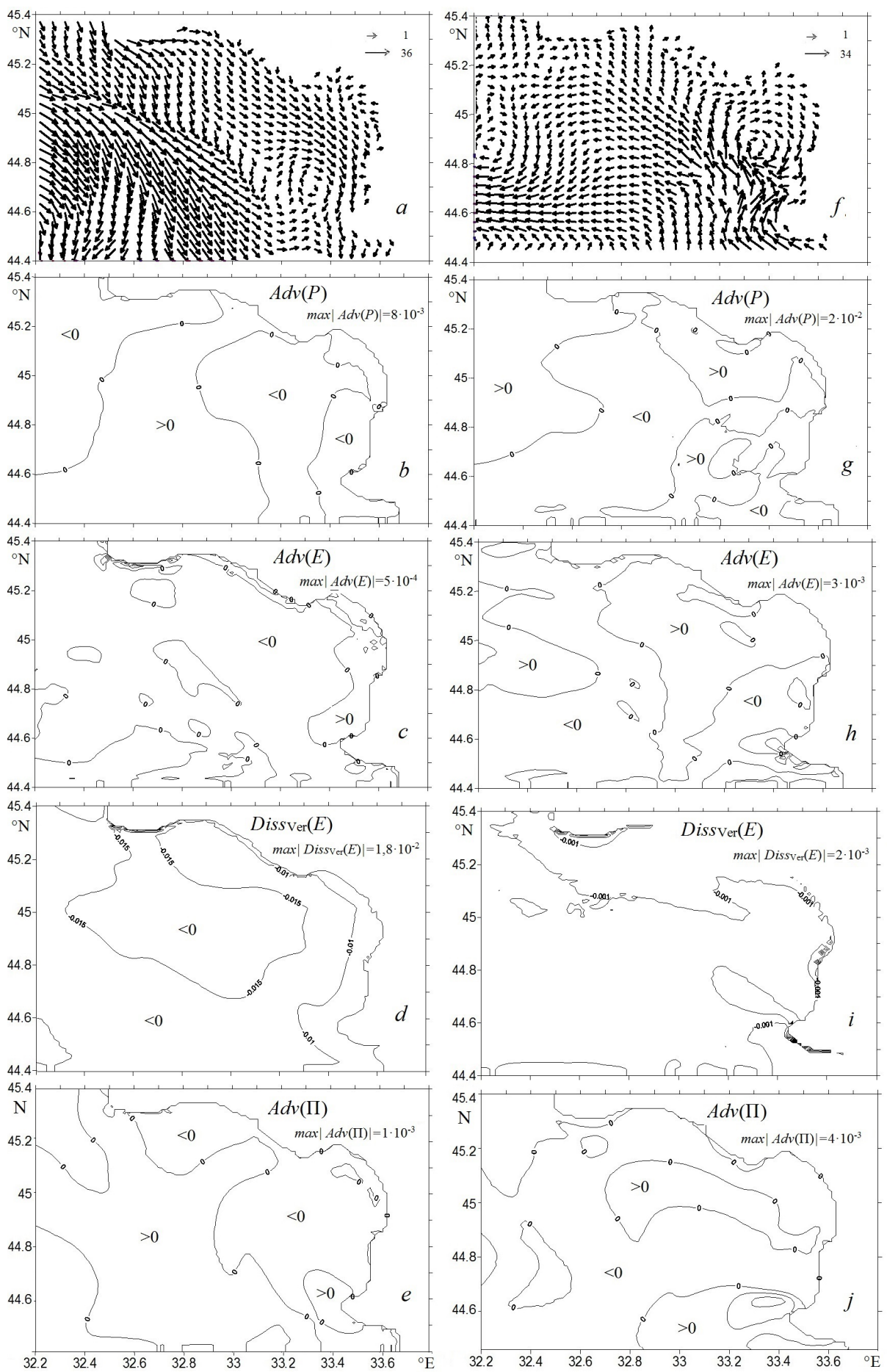

F i g. 6. Data fields obtained at the $5 \mathrm{~m}$ depth on September 17, 2007: currents, $(\mathrm{cm} / \mathrm{s})(a)$; $\operatorname{Adv}(P), \mathrm{erg} /\left(\mathrm{s}^{\cdot} \mathrm{cm}^{3}\right)(b) ; \operatorname{Adv}(E), \mathrm{erg} /\left(\mathrm{s}^{\cdot} \mathrm{cm}^{3}\right)(c) ; \operatorname{Diss} V e r(E), \operatorname{erg} /\left(\mathrm{s}^{\cdot} \mathrm{cm}^{3}\right)(d) ; \operatorname{Adv}(\Pi), \mathrm{erg} /\left(\mathrm{s}^{\cdot} \mathrm{cm}^{3}\right)(e) ;-$ and on September 22, 2007: currents (cm/s) (f); $\operatorname{Adv}(P), \operatorname{erg} /\left(\mathrm{s}^{\cdot} \mathrm{cm}^{3}\right)(g) ; \operatorname{Adv}(E), \operatorname{erg} /\left(\mathrm{s}^{\cdot} \mathrm{cm}^{3}\right)(h)$;

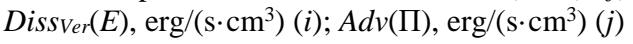


We also analyzed the spatial distributions of $\tau \rightarrow E=u_{0} \tau^{x}+v_{0} \tau^{y}$ term (which is obtained by integrating the $\mathrm{KE}$ budget equation along the vertical and has $\mathrm{erg} /\left(\mathrm{s} \cdot \mathrm{cm}^{2}\right)$ dimensionality) that determines the wind contribution to the kinetic energy. In Fig. 7, $a$ and $b$ the field of currents on the upper horizon and $\tau \rightarrow E$ field on September 18 are presented. The influx of energy from the wind prevailed in almost the entire region, except for the Kalamita Bay. In the zone where the wind force work was negative, a horizontal shear took place in the velocity field: on the shelf, the current was directed to the northeast, and in the deep-water part of the sea - to the southwest. Thus, shear instability of the current could be a possible mechanism for the formation of an anticyclonic eddy in the Kalamita Bay.

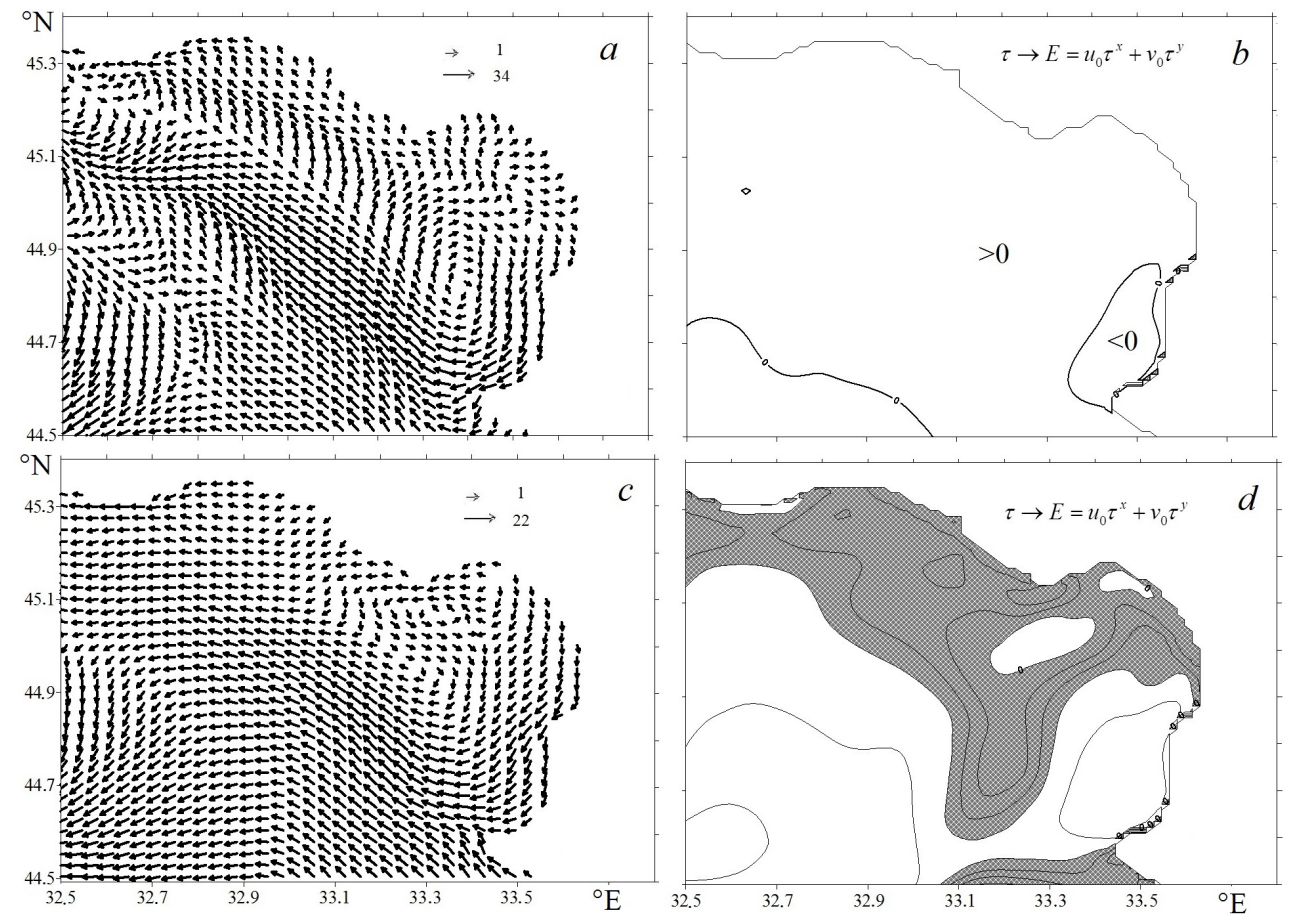

F i g. 7. Data fields obtained at the upper horizon on September 18, 2007: $a$ - currents, $\mathrm{cm} / \mathrm{s} ; b-$ the values of $\tau \rightarrow E=u_{0} \tau^{x}+v_{0} \tau^{y}$, erg/(s. $\left.\mathrm{cm}^{2}\right)$, - and on September 21, 2007: $c$ - currents, $\mathrm{cm} / \mathrm{s} ; d$ - the values of $\tau \rightarrow E=u_{0} \tau^{x}+v_{0} \tau^{y}$, erg/(s· $\left.\mathrm{cm}^{2}\right)$. The dashed areas in Fig. 7, $d$ correspond to the minimum values of $\tau \rightarrow E$

In the period under consideration, submesoscale eddies with less than $5 \mathrm{~km}$ diameters were obtained in the upper layer. A possible formation mechanism is the current that flows around the coastline and bottom topography inhomogeneities under the action of weak winds. In Fig. 7, $c$ and $d$ the field of currents and the spatial distribution of $\tau \rightarrow E=u_{0} \tau^{x}+v_{0} \tau^{y}$ term that determines the wind contribution to the kinetic energy for September 21. Note that the eddies were formed in the zones corresponding to $\tau \rightarrow E$ minimum values. 


\section{Conclusion}

On the basis of the hydrodynamic model and the observation data of temperature and salinity obtained during the hydrological survey on R/V Eksperiment in 2007, the dynamic and energy characteristics of the Black Sea coastal circulation (off the coast of western Crimea and in the Sevastopol region) were calculated with a high spatial resolution ( $1.6 \mathrm{~km}$ horizontally and 30 horizons vertically).

Based on a comparison of the results of two numerical experiments on the calculation of hydrophysical fields with the assimilation of hydrological measurement data, taking into account the heterogeneity and anisotropy of errors in the estimates of temperature and salinity fields and without taking them into account, it is shown that taking into account the heterogeneity and anisotropy leads to qualitative and quantitative differences in hydrodynamic fields (strengthening of currents, change of their direction, more pronounced eddy formations). In this case, the root-mean-square errors of thermohaline field estimates decreased.

The kinetic energy variation is mainly due to wind action, vertical friction and pressure work; potential energy variation - by potential energy advection and horizontal turbulent diffusion.

The following circulation features have been reconstructed: an anticyclonic eddy with a radius of about $15 \mathrm{~km}$ in the Kalamita Bay in the upper water layer, an anticyclonic eddy with a radius of about $15 \mathrm{~km}$ between $32.2^{\circ} \mathrm{E}$ and $32.6^{\circ} \mathrm{E}$ in the entire water layer, an intense current near Sevastopol and along the western coast of the Crimea, directed to the north and north-west, eddies with a radius of less than $10 \mathrm{~km}$ of different rotation signs in the upper layer along the coast.

Possible mechanisms for the generation of coastal mesoscale and submesoscale eddies in the considered coastal zone could be a horizontal velocity shear (resulting from the negative work of the wind force) and flowing around the coastline and bottom topography inhomogeneities by the current.

\section{REFERENCES}

1. Timchenko, I.E., 1973. Prediction of the Vector of Currents Velocity in a Sea from a Time series of Observations. In: MHI, 1973. Marine Hydrophysical Research. Sevastopol: MHI NASU. No. 2, pp. 105-118 (in Russian).

2. Timchenko, I.E., 1981. Dynamic-Stochastic Models of the Ocean State. Kiev: Naukova Dumka, 191 p. (in Russian).

3. Knysh, V.V., Moiseenko, V.A., Sarkisian, A.S. and Timchenko, I.E., 1980. Complex Use of Measurements in Hydrophysical Study Grounds of the Ocean in Four-Dimensional Analysis. Reports of the USSR Academy of Sciences, 252(4), pp. 832-836.

4. Knysh, V.V., 1982. Multielement Four-Dimensional Analysis of the Major Hydrophysical Fields of the Ocean. Izvestiya of the Academy of Sciences of the USSR. Atmospheric and Oceanic Physics, 18(4), pp. 391-398.

5. Sakawa, Y., 1972. Optimal Filtering in Linear Distributed-Parameter Systems. International Journal of Control, 16(1), pp. 115-127. https://doi.org/10.1080/00207177208932247

6. Demyshev, S.G. and Korotaev, G.K., 1993. Numerical Experiments on the Four-Dimensional Assimilation of the Observation Data Derived in the Black Sea in June 1984 on the Basis of a Numerical Energy-Balanced Model. Physical Oceanography, 4(3), pp. 193-205. https://doi.org/10.1007/BF02197317

7. Knysh, V.V., Korotaev, G.K., Mizyuk, A.I. and Sarkisyan, A.S., 2012. Assimilation of Hydrological Observation Data for Calculating Currents in Seas and Oceans. Izvestiya, Atmospheric and Oceanic Physics, 48(1), pp. 57-73. doi:10.1134/S0001433812010057

8. Tanajura, C., Costa, F., Silva, R., Ruggiero, G. and Daher, V., 2013. Assimilation of Sea Surface Height Anomalies into HYCOM with an Optimal Interpolation Scheme over the 
Atlantic Ocean METAREA V. Brazilian Journal of Geophysics, 31(2), pp. 257-270. http://dx.doi.org/10.22564/rbgf.v31i2.293

9. Belyaev, K.P., Tanajura, C.A.S. and Tuchkova, N.P., 2012. Comparison of Methods for ARGO Drifters Data Assimilation into a Hydrodynamical Model of the Ocean. Oceanology, 52(5), pp. 593-603. doi:10.1134/S0001437012050025

10. Agoshkov, V.I., Parmuzin, E.I. and Shutyaev, V.P., 2013. Observational Data Assimilation in the Problem of Black Sea Circulation and Sensitivity Analysis of Its Solution. Izvestiya, Atmospheric and Oceanic Physics, 49(6), pp. 592-602. doi:10.1134/S0001433813060029

11. Feoktistov, A.S. and Nezhevenko, E.S., 2015. Forecasting of Dynamic Processes on the Earh Surface Based on Data Assimilation. Vestnik NSU. Series: Information Technologies, 13(2), pp. 103-115 (in Russian).

12. Zelenko, A.A., Vil'fand, R.M., Resnyanskii, Y.D., Strukov, B.S., Tsyrulnikov, M.D. and Svirenko, P.I., 2016. An Ocean Data Assimilation System and Reanalysis of the World Ocean Hydrophysical Fields. Izvestiya, Atmospheric and Oceanic Physics, 52(4), pp. 443-454. https://doi.org/10.1134/S0001433816040149

13. Zalesny, V.B., Agoshkov, V.I., Shutyaev, V.P., Le Dimet, F. and Ivchenko, B.O., 2016. Numerical Modeling of Ocean Hydrodynamics with Variational Assimilation of Observational Data. Izvestiya, Atmospheric and Oceanic Physics, 52(4), pp. 431-442. https://doi.org/10.1134/S0001433816040137

14. Dorofeev, V.L. and Sukhikh, L.I., 2017. Study of Long-Term Variability of Black Sea Dynamics on the Basis of Circulation Model Assimilation of Remote Measurements. Izvestiya, Atmospheric and Oceanic Physics, 53(2), pp. 224-232. https://doi.org/10.1134/S0001433817020025

15. Kaurkin, M.N., Ibrayev, R.A. and Belyaev, K.P., 2018. Assimilation of the AVISO Altimetry Data into the Ocean Dynamics Model with a High Spatial Resolution Using Ensemble Optimal Interpolation (EnOI). Izvestiya, Atmospheric and Oceanic Physics, 54(1), pp. 56-64. https://doi.org/10.1134/S0001433818010073

16. Agoshkov, V.I., Zalesny, V.B. and Sheloput, T.O., 2020. Variational Data Assimilation in Problems of Modeling Hydrophysical Fields in Open Water Areas. Izvestiya, Atmospheric and Oceanic Physics, 56(3), pp. 253-267. https://doi.org/10.1134/S0001433820030020

17. Demyshev, S.G., 2012. A Numerical Model of Online Forecasting Black Sea Currents. Izvestiya, Atmospheric and Oceanic Physics, 48(1), pp. 120-132. doi:10.1134/S0001433812010021

18. Pacanowski, R.C. and Philander, S.G.H., 1981. Parameterization of Vertical Mixing in Numerical Models of Tropical Oceans. Journal of Physical Oceanography, 11(11), pp. 14431451. https://doi.org/10.1175/1520-0485(1981)011<1443:POVMIN>2.0.CO;2

19. Ratner, Y.B., Martynov, M.V., Bayankina, T.M. and Borodin, S.V., 2005. [Information Flows in the System of Operational Monitoring of Hydrophysical Fields of the Black Sea and Automation of their Processing]. Monitoring Systems of Environment, (8), pp. 140-149 (in Russian).

20. ALADIN international team, 1997. The ALADIN Project: Mesoscale Modelling Seen as a Basic Tool for Weather Forecasting and Atmospheric Research. World Meteorological Organization Bulletin, 46(4), pp.317-324. Available at: http://www.umrcnrm.fr/aladin/IMG/pdf/ALADIN_PROJECT-pdf_-_Adobe_Acrobat_Professional.pdf [Accessed: 23 November 2020].

21. Suvorov, A.M., Andryushchenko, E.G., Godin, E.A., Ingerov, A.V., Kasyanenko, T.E., Plastun, T.V. and Khaliulin, A.H., 2003. [Oceanological Data Bank of MGI NASU: Content and Structure of Databases, Database Management System]. Monitoring Systems of Environment, 1(5), pp. 130137 (in Russian).

22. Harten, A., 1983. High Resolution Schemes for Hyperbolic Conservation Laws. Journal of Computational Physics, 49(3), pp. 357-393. https://doi.org/10.1016/0021-9991(83)90136-5

23. Demyshev, S.G., 2004. Energy of the Black Sea Climatic Circulation. Part I: Discrete Equations of the Rate of Change of Kinetic and Potential Energy. Meteorologiya $i$ Gidrologiya, (9), pp. 65-80 (in Russian).

24. Demyshev, S.G., 2004. Energy of the Black Sea Climatic Circulation. Part II: Numerical Analysis of Climatic Energy. Meteorologiya i Gidrologiya, (10), pp. 74-86 (in Russian).

25. Evstigneeva, N. and Demyshev, S., 2019. Analysis of Circulation near the Coast of Western Crimea and in the Region of Sevastopol with Assimilation of Temperature and Salinity Observations. IOP Conference Series: Earth and Environmental Sciences, 386, 012047. doi:10.1088/1755-1315/386/1/012047 
About the authors:

Sergey G. Demyshev, Principal Research Associate, Head of Wave Theory Department, Marine Hydrophysical Institute of RAS (2 Kapitanskaya str., Sevastopol, 299011, Russian Federation), Dr.Sci. (Phys.-Math.), SPIN-code: 827-783, ORCID ID: 0000-0002-5405-2282, ResearcherID: C1729-2016, Scopus Author ID: 6603919865, demyshev@gmail.ru

Natalia A. Evstigneeva, Research Associate, Marine Hydrophysical Institute of RAS (2 Kapitanskaya str., Sevastopol, 299011, Russian Federation), Ph.D. (Phys.-Math.), SPIN-code: 826959, ORCID ID: 0000-0002-8636-7289, ResearcherID: C-1922-2016, Scopus Author ID: 55236367400,naevstigneeva@yandex.ru

Dmitry V. Alekseev, Scientific Secretary, Marine Hydrophysical Institute of RAS (2 Kapitanskaya str., Sevastopol, 299011, Russian Federation), Ph. D. (Phys.-Math.), SPIN-code: 767834, ResearcherID: I-3548-2017, ORCID ID: 0000-0003-4006-0967, Scopus Author ID: 8284177400, dalexeev@rambler.ru

Ol'ga A. Dymova, Senior Research Associate, Marine Hydrophysical Institute of RAS (2 Kapitanskaya str., Sevastopol, 299011, Russian Federation), Ph. D. (Phys.-Math.), SPIN-code: 796208, ORCID ID: 0000-0003-4036-2447, ResearcherID: P-9669-2015, Scopus Author ID: 6508381809, olgadym@yahoo.com

Nadezhda A. Miklashevskaya, Junior Research Associate, Marine Hydrophysical Institute of RAS (2 Kapitanskaya str., Sevastopol, 299011, Russian Federation), SPIN-code: 543-558, ORCID ID: 0000-0003-2619-343X, ResearcherID: P-2167-2017, Scopus Author ID: 8523715300, nmikl@rambler.ru

Contribution of the co-authors:

Sergey G. Demyshev - four-dimensional analysis of temperature, salinity and current velocity fields based on a modified Kalman filter with assimilation of observations of hydrological temperature and salinity survey in September 2007 and processing of calculation results; analysis of the obtained hydrophysical and energy fields for the coastal zone and study (on its basis) of possible physical mechanisms for the generation of meso- and sub-mesoscale eddies and jet currents off the western coast of Crimea and in the area of Sevastopol; preparation of the paper text

Natalia A. Evstigneeva - four-dimensional analysis of temperature, salinity and current velocity fields based on a modified Kalman filter with assimilation of observations of hydrological temperature and salinity survey in September 2007 and processing of calculation results; comparison and analysis of the results of numerical experiments for 2007 carried out using the procedure of optimal interpolation and four-dimensional assimilation of observational data; analysis of the obtained hydrophysical and energy fields for the coastal zone and study (on its basis) of possible physical mechanisms for the generation of meso- and sub-mesoscale eddies and jet currents off the western coast of Crimea and in the area of Sevastopol; preparation of the paper text

Dmitry V. Alekseev - four-dimensional analysis of temperature, salinity and current velocity fields based on a modified Kalman filter with assimilation of observations of hydrological temperature and salinity survey in September 2007 and processing of calculation results

Ol'ga A. Dymova - four-dimensional analysis of temperature, salinity and current velocity fields based on a modified Kalman filter with assimilation of observations of hydrological temperature and salinity survey in September 2007 and processing of calculation results; comparison and analysis of the results of numerical experiments for 2007 carried out using the procedure of optimal interpolation and four-dimensional assimilation of observational data

Nadezhda A. Miklashevskaya - comparison and analysis of the results of numerical experiments for 2007 carried out using the procedure of optimal interpolation and four-dimensional assimilation of observational data; analysis of the obtained hydrophysical and energy fields for the coastal zone and study (on its basis) of possible physical mechanisms for the generation of mesoand sub-mesoscale eddies and jet currents off the western coast of Crimea and in the area of Sevastopol; analysis of the obtained hydrophysical and energy fields for the coastal zone and study (on its basis) of possible physical mechanisms for the generation of meso- and sub-mesoscale eddies and jet currents off the western coast of Crimea and in the area of Sevastopol

All the authors have read and approved the final manuscript.

The authors declare that they have no conflict of interest. 